\title{
Adverse Effects of AMP-Activated Protein Kinase $\alpha 2$-Subunit Deletion and High-Fat Diet on Heart Function and Ischemic Tolerance in Aged Female Mice
}

\author{
K. SLÁMOVÁ ${ }^{1}$, F. PAPOUŠEK ${ }^{1}$, P. JANOVSKÁ ${ }^{1}$, J. KOPECKÝ $^{1}$, F. KOLÁ $^{1}$ \\ ${ }^{1}$ Institute of Physiology of the Czech Academy of Sciences, Prague, Czech Republic
}

Received December 9, 2014

Accepted July 10, 2015

On-line November 24, 2015

\begin{abstract}
Summary
AMP-activated protein kinase (AMPK) plays a role in metabolic regulation under stress conditions, and inadequate AMPK signaling may be also involved in aging process. The aim was to find out whether AMPK a2-subunit deletion affects heart function and ischemic tolerance of adult and aged mice. AMPK a2 ${ }^{-1-}$ (KO) and wild type (WT) female mice were compared at the age of 6 and 18 months. KO mice exhibited subtle myocardial AMPK a2-subunit protein level, but no difference in AMPK a1-subunit was detected between the strains. Both a1- and a2-subunits of AMPK and their phosphorylation decreased with advanced age. Left ventricular fractional shortening was lower in KO than in WT mice of both age groups and this difference was maintained after high-fat feeding. Infarct size induced by global ischemia/reperfusion of isolated hearts was similar in both strains at 6 months of age. Aged WT but not KO mice exhibited improved ischemic tolerance compared with the younger group. High-fat feeding for 6 months during aging abolished the infarct size-reduction in WT without affecting KO animals; nevertheless, the extent of injury remained larger in KO mice. The results demonstrate that adverse effects of AMPK a2-subunit deletion and high-fat feeding on heart function and myocardial ischemic tolerance in aged female mice are not additive.
\end{abstract}

\section{Key words}

AMP kinase - Ischemia/reperfusion - Myocardial infarction • Aging $\bullet$ High-fat diet

\section{Corresponding author}

F. Kolár, Institute of Physiology of the Czech Academy of Sciences, Vídeňská 1083, 14220 Prague, Czech Republic. Fax: +42024106 2125. E-mail: kolar@biomed.cas.cz

\section{Introduction}

AMP-activated protein kinase (AMPK) is a heterotrimeric serine/threonine kinase expressed in most mammalian tissues including myocardium. It acts as a cellular fuel gauge in response to a depletion of ATP levels (Hardie 2003) and its activation is essential for the control of whole body energy homeostasis during physiological and pathological stresses such as exercise, pressure overload, nutritional deprivation, hypoxia or ischemia. Once activated, AMPK phosphorylates a number of target proteins resulting in a stimulation of ATP-producing processes and an inhibition of energyconsuming biosynthetic pathways. Increased glucose uptake, glycogenolysis and glycolysis as well as increased fatty acid transport and oxidation are the main acute metabolic actions of AMPK aiming at a restoration of cellular energy balance (for review see Hardie and Carling 1997, Steinberg and Kemp 2009, Wang et al. 2012, Zaha and Young 2012). In addition, AMPK inhibits protein synthesis, stimulates protein degradation and promotes autophagy in line with its role in providing fuel during energy deprivation (Zaha and Young 2012).

Rapid activation of AMPK during myocardial ischemia (Kudo et al. 1995, Folmes et al. 2009) may help to preserve cardiac function and viability by stimulating glycolytic ATP production. On the other hand, the AMPK-dependent stimulation of fatty acid oxidation at reperfusion occurs at the expense of glucose oxidation with potentially harmful consequences due to acidosis (Liu et al. 2002, Dyck and Lopaschuk 2006). Indeed, a number but not all studies demonstrated beneficial 
effects of AMPK against various manifestations of acute ischemia/reperfusion (I/R) injury (for review see Zaha and Young 2012) and this issue is still a matter of debate.

Cardiovascular aging and senescence is associated with complex alterations at the molecular level resulting in unfavorable myocardial biochemical and structural remodeling and eventually in impaired cardiac contractility and pump function (Lakatta and Sollott 2002, Ferrari et al. 2003). It has been repeatedly demonstrated that aged hearts are more susceptible to $I / R$ injury, and their endogenous protective mechanisms activated by various forms of pre- and postconditioning are attenuated or lost (for review see Boengler et al. 2009). The cause is obviously multifactorial and still poorly understood (Ashton et al. 2006).

AMPK controls various signaling pathways involved in the aging process (Salminen and Kaarniranta 2012) and its chronic pharmacological activation has been proposed as a strategy for delaying aging and extending the lifespan (McCarty 2004). Senescent mice exhibited significant reduction in both AMPK $\alpha 1$ and $\alpha 2$ isoform activities in left ventricular myocardium (Turdi et al. 2010) and the stimulation of AMPK $\alpha 2$ activity was blunted in skeletal muscle of old rats (Reznick et al. 2007). It has been shown that AMPK deficiency exacerbated cardiac contractile dysfunction in senescent mice (Turdi et al. 2010). In addition, AMPK has been implicated in the mechanism of pronounced protective effect of caloric restriction against myocardial I/R injury in aged mice (Edwards et al. 2010). On the other hand, Gonzales et al. (2004) suggested that the age-associated decline in myocardial hypoxic tolerance is caused by neither changes in AMPK activity nor blunted AMPK response to hypoxia.

The purpose of the present study was to find out whether AMPK $\alpha 2$-subunit deletion would affect heart function and ischemic tolerance of adult and aged mice. As high circulation levels of fatty acids can contribute to myocardial I/R injury (Lopaschuk et al. 2007) and AMPK $\alpha 2$-subunit plays an important role in fatty acid uptake (Abbott et al. 2012) and prevention of metabolic disorders induced by high-fat (HF) feeding (Fujii et al. 2008), we also assessed functional changes and the extent of I/R injury in hearts of mice fed HF diet for 6 months at advanced age. We hypothesized that deletion of AMPK $\alpha 2$-subunit, which is the predominant AMPK $\alpha$-subunit expressed in mice hearts ( $\mathrm{Li}$ et al. 2006), will impair heart function and ischemic tolerance of aged mice and these effects will be further exacerbated by HF diet.

\section{Methods}

\section{Experimental animals}

6-month-old (adult) and 18-month-old (aged) whole-body AMPK $\alpha 2$-subunit knock-out (KO) female mice backcrossed to $\mathrm{C} 57 \mathrm{BL} / 6 \mathrm{~J}$ mice for more than nine generations (Viollet et al. 2003, Jeleník et al. 2010) and their wild-type (WT) littermate controls were employed. Mice were housed in a controlled environment $\left(21^{\circ} \mathrm{C}\right.$; 12-h light-dark cycle) with free access to water and standard chow diet (extruded Ssniff R/M-H diet; Ssniff Spezialdieten $\mathrm{GmbH}$, Soest, Germany). Some mice were randomly assigned to corn oil-based HF diet from $12^{\text {th }}$ to $18^{\text {th }}$ month of age. Composition of the diets is given in Table 1 (for further details, see Kuda et al. 2009). All mice were used in ad libitum fed state. The study was conducted in accordance with the Guide for the Care and Use of Laboratory Animals published by the US National Institutes of Health (NIH publication no. 85-23, revised 1996). The experimental protocols were approved by the Animal Care and Use Committee of the Institute of Physiology of the Czech Academy of Sciences.

Table 1. Macronutrient composition and energy content of diets and fatty acid composition of dietary lipids.

\begin{tabular}{lcc}
\hline & $\begin{array}{c}\text { Standard } \\
\text { diet }\end{array}$ & $\begin{array}{c}\text { High-fat } \\
\text { diet }\end{array}$ \\
\hline $\begin{array}{l}\text { Macronutrient composition } \\
\text { (\% diet, wt/wt) }\end{array}$ & & \\
Lipid & 3.4 & 35.2 \\
Carbohydrate & 55.3 & 35.4 \\
Protein & 19.3 & 20.5 \\
Energy density (kJ/g) & 16.3 & 22.8 \\
Fatty acid composition & & \\
(g/100 g) & & \\
SFA & 18.4 & 22.1 \\
MUFA & 17.8 & 28.5 \\
$n-6$ PUFA & 57.9 & 47.7 \\
$n-3$ PUFA & 6.0 & 1.8 \\
\hline
\end{tabular}

SFA, saturated fatty acids; MUFA, monounsaturated fatty acids; PUFA, polyunsaturated fatty acids.

\section{Quantification of AMPK}

Mice were killed by cervical dislocation, hearts were dissected and frozen in liquid nitrogen. The heart lysates were prepared by homogenization in liquid 
nitrogen. The total contents of catalytic $\alpha 1-$ and a2-subunit of AMPK and the phosphorylated form of AMPK were determined by Western blotting as described previously (Kůs et al. 2008, Matějková et al. 2004).

\section{Echocardiography}

The echocardiographic evaluation of the geometrical and functional parameters of the LV was performed using the GE Vivid 7 Dimension (GE Vingmed Ultrasound, Horten, Norway) with a $12 \mathrm{MHz}$ linear matrix probe M12L. The animals were anesthetized by the inhalation of $2 \%$ isoflurane (Aerrane, Baxter SA) and their rectal temperature was maintained within 36.5 and $37.5^{\circ} \mathrm{C}$ by a heated table throughout the measurements. For the baseline evaluation, the following diastolic and systolic dimensions of the LV were measured: the posterior wall thickness (PWTd and PWTs), anterior wall thickness (AWTd and AWTs), and the cavity diameter (LVDd and LVDs). From these dimensions, the main functional parameter, fractional shortening (FS) was derived by the following formula: FS $[\%]=100 \times($ LVDd - LVDs $) /$ LVDd .

\section{Isolated perfused hearts}

Animals were anesthetized with intraperitoneal injection of thiopental (VUAB Pharma, Czech Republic). Hearts were rapidly excised and perfused according to Langendorff under constant pressure of $80 \mathrm{~mm} \mathrm{Hg}$ with non-recirculating modified Krebs-Henseleit solution (mmol/l: $118.0 \mathrm{NaCl}, 25.0 \mathrm{NaHCO}_{3}, 4.7 \mathrm{KCl}, 1.2 \mathrm{MgSO}_{4}$, $1.2 \mathrm{KH}_{2} \mathrm{PO}_{4}, 2.5 \mathrm{CaCl}_{2}, 0.5$ EDTA, 11.0 glucose) gassed with $95 \% \mathrm{O}_{2}$ and $5 \% \mathrm{CO}_{2}(\mathrm{pH} 7.4)$ and maintained at $37^{\circ} \mathrm{C}$. Coronary flow was measured by timed collection of coronary effluent and normalized to heart weight. After $20 \mathrm{~min}$ of stabilization, the spontaneously beating hearts were subjected to $45 \mathrm{~min}$ of global no-flow normothermic ischemia and $60 \mathrm{~min}$ of reperfusion.

\section{Infarct size determination}

A $2 \mathrm{ml}$ bolus of $1 \% 2,3,5$ triphenyltetrazolium chloride (TTC) was injected through the aorta followed by incubation of the heart in TTC for $20 \mathrm{~min}$ at $25^{\circ} \mathrm{C}$ and fixation overnight in $10 \%$ neutral formaldehyde solution. After the right ventricle (RV) separation, the left ventricle (LV including the septum) was cut perpendicularly to the long axis into $0.5 \mathrm{~mm}$ thick slices. The infarct size (TTC-negative) and the size of the LV were determined from photographs by a computerized planimetric method using the software Ellipse (ViDiTo, Slovakia). The infarct size was normalized to the size of the LV.

\section{Statistical analysis}

Analyses were performed using GraphPad Prism software (version 6.01; Graph Pad Inc., San Diego, CA). A two-way ANOVA (with genotype and experimental conditions as categories) was carried out to determine significant interactions, followed by a Tukey's post-hoc multiple-comparisons test to examine differences between groups. All values are expressed as means \pm SEM with $p<0.05$ considered as statistically significant.

\section{Results}

\section{Basic characteristics}

Body weight was significantly higher in aged mice than in adult ones and it was further increased by HF diet-feeding without any effect of the genotype. Heart weight was also higher in mice kept on HF diet and the increase was more pronounced in the $\mathrm{KO}$ group. However, no difference among groups was observed in relative heart weight. Aging was associated with a significant decrease in hematocrit level regardless the genotype or diet (Table 2).

Table 2. Weight parameters and hematocrit in adult and aged AMPK a2 ${ }^{-1-}$ and wild-type mice fed standard or high-fat diet.

\begin{tabular}{lccccc}
\hline & $\mathbf{n}$ & BW (g) & HW (mg) & HW/BW (mg/g) & Hematocrit (\%) \\
\hline Adult $W T$ & 8 & $21.3 \pm 0.6$ & $100.6 \pm 3.6$ & $4.741 \pm 0.143$ & $47.2 \pm 0.7$ \\
Adult KO & 11 & $21.4 \pm 0.4$ & $97.7 \pm 3.6$ & $4.583 \pm 0.173$ & $46.6 \pm 0.7$ \\
Aged $W T$ & 11 & $24.4 \pm 0.7^{*}$ & $103.2 \pm 9.8$ & $4.375 \pm 0.310$ & $40.4 \pm 0.8^{*}$ \\
Aged KO & 14 & $24.6 \pm 0.3^{*}$ & $107.9 \pm 3.6$ & $4.393 \pm 0.128$ & $40.7 \pm 0.9^{*}$ \\
Aged $W T$ HF & 11 & $33.3 \pm 1.7^{* \dagger}$ & $138.5 \pm 5.2^{*}$ & $4.291 \pm 0.324$ & $42.3 \pm 1.4^{*}$ \\
Aged KO HF & 11 & $35.1 \pm 2.5^{* \dagger}$ & $162.3 \pm 4.0^{* *}$ & $4.371 \pm 0.355$ & $40.4 \pm 1.8^{*}$ \\
\hline
\end{tabular}

BW, body weight; HW, heart weight; HW/BW, relative heart weight; KO, AMPK a2 ${ }^{-1}$ mice; WT, wild-type mice; HF, high-fat diet; $\mathrm{n}$, number of animals. Values are means $\pm \mathrm{SEM} ;{ }^{*} p<0.05$ vs. adult; ${ }^{\dagger} p<0.05$ vs. standard diet; ${ }^{\ddagger} p<0.05$ vs. WT. 
Protein expression and phosphorylation of AMPK

Western blot analysis of AMPK in the hearts from standard diet-fed mice (Fig. 1A) revealed agedependent decrease in the levels of both $\alpha 1$-subunit (Fig. 1B) and $\alpha 2$-subunit (Fig. 1C). Whereas the level of AMPK $\alpha 1$-subunit was comparable to that of WT mice
(Fig. 1B), a negligible amount of the $\alpha 2$-subunit was present in the KO mice, independent of age (Fig. 1C). Phosphorylated AMPK levels were markedly reduced in KO compared with WT mice and they were also decreased during aging in both genotypes (Fig. 1D).
A
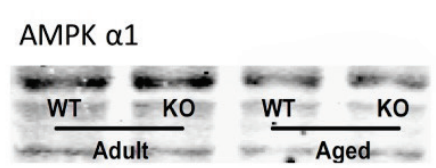

AMPK $\alpha 2$

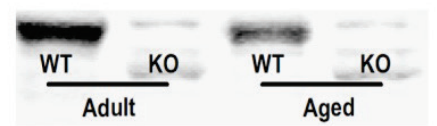

pAMPK

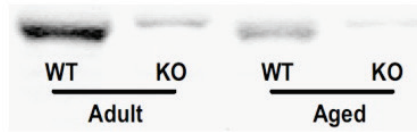

C

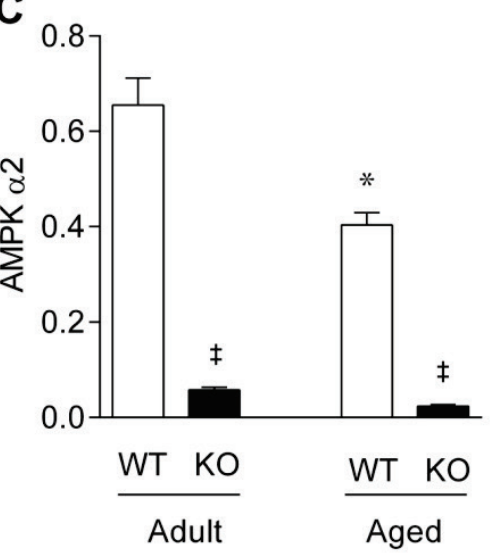

B

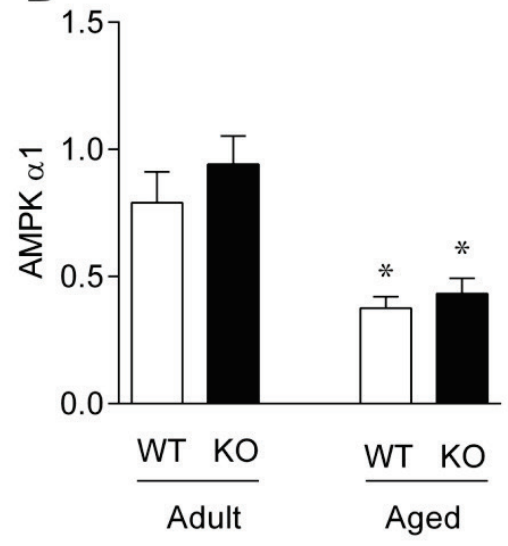

D

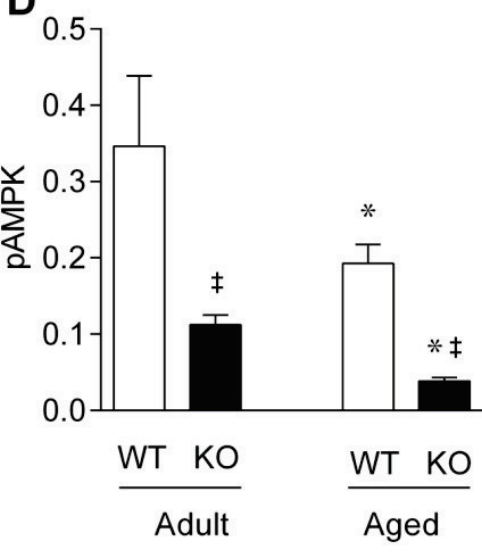

Fig. 1. Representative blots (A) and myocardial protein levels of AMPK a1-subunit (B), AMPK a2-subunit (C) and phosphorylated AMPK (D) in adult and aged AMPK a2 ${ }^{--}$(KO) and wild-type (WT) mice fed standard diet. Values are means \pm SEM; $\mathrm{n}=7-10$ in each group; $* p<0.05$ vs. adult; ${ }^{\ddagger} p<0.05$ vs. WT.

Table 3. Heart rate and echocardiographic parameters of adult and aged AMPK a2 ${ }^{-/-}$and wild-type mice fed standard or high-fat diet.

\begin{tabular}{|c|c|c|c|c|c|c|c|c|}
\hline & $\mathbf{n}$ & $\begin{array}{c}\text { HR } \\
\text { (beat/min) }\end{array}$ & $\begin{array}{c}\text { LVDd } \\
(\mathrm{mm})\end{array}$ & $\begin{array}{l}\text { LVDs } \\
(\mathbf{m m})\end{array}$ & $\begin{array}{c}\text { AWTd } \\
(\mathbf{m m})\end{array}$ & $\begin{array}{c}\text { PWTd } \\
(\mathbf{m m})\end{array}$ & $\begin{array}{c}\text { AWTs } \\
(\mathbf{m m})\end{array}$ & $\begin{array}{l}\text { PWTs } \\
(\mathbf{m m})\end{array}$ \\
\hline Adult WT & 7 & $508 \pm 12$ & $3.40 \pm 0.4$ & $1.98 \pm 0.06$ & $0.75 \pm 0.04$ & $0.71 \pm 0.03$ & $1.15 \pm 0.04$ & $1.17 \pm 0.04$ \\
\hline Adult $K O$ & 10 & $516 \pm 8$ & $3.67 \pm 0.06$ & $2.42 \pm 0.05^{\ddagger}$ & $0.73 \pm 0.01$ & $0.70 \pm 0.02$ & $1.12 \pm 0.02$ & $1.11 \pm 0.03$ \\
\hline Aged WT & 10 & $539 \pm 9$ & $3.42 \pm 0.08$ & $2.04 \pm 0.08$ & $0.74 \pm 0.02$ & $0.75 \pm 0.02$ & $1.18 \pm 0.02$ & $1.19 \pm 0.03$ \\
\hline Aged KO & 15 & $561 \pm 8$ & $3.66 \pm 0.07$ & $2.48 \pm 0.07^{\ddagger}$ & $0.73 \pm 0.02$ & $0.73 \pm 0.03$ & $1.14 \pm 0.02$ & $1.12 \pm 0.02 *$ \\
\hline Aged WT HF & 10 & $525 \pm 14$ & $3.74 \pm 0.04$ & $2.45 \pm 0.06$ & $0.79 \pm 0.03$ & $0.80 \pm 0.02$ & $1.19 \pm 0.02$ & $1.18 \pm 0.03$ \\
\hline Aged KO HF & 13 & $542 \pm 10$ & $4.08 \pm 0.10^{\dagger *}$ & $2.90 \pm 0.14^{\dagger \dagger}$ & $0.78 \pm 0.02$ & $0.81 \pm 0.03$ & $1.16 \pm 0.02$ & $1.15 \pm 0.03$ \\
\hline
\end{tabular}

$\mathrm{KO}$, AMPK $\mathrm{a2}^{-1-}$ mice; WT, wild-type mice; HF, high-fat diet; HR, heart rate; LVDd, diastolic cavity diameter; LVDs, systolic cavity diameter; AWTd, diastolic anterior wall thickness; PWTd, diastolic posterior wall thickness; AWTs, systolic anterior wall thickness; PWTs, systolic posterior wall thickness; $\mathrm{n}$, number of animals. Values are means $\pm \mathrm{SEM} ;{ }^{\dagger} p<0.05$ vs. standard diet; ${ }^{\ddagger} p<0.05$ vs. WT. 


\section{Heart function}

Echocardiography was used to assess effects of age, diet and AMPK deletion in separate groups of mice. LVDs significantly increased in response to AMPK deletion in all groups. Both LVDd and LVDs were significantly larger in the HF diet-fed as compared with the standard diet-fed aged mice, but this effect reached statistical significance only in the $\mathrm{KO}$ animals. Wall thickness measurements did not show any significant differences among groups, except for a slight decrease in PWTs in aged KO compared to WT mice fed standard diet (Table 3).

FS was lower in all groups of $\mathrm{KO}$ mice compared to corresponding WT mice and it was not significantly affected by aging. Feeding HF diet decreased this index of LV systolic function in WT animals without having a significant effect in $\mathrm{KO}$ mice, despite the fact that 3 animals out of 13 in this later group exhibited a marked drop of FS to around $20 \%$. Only a combination of aging and HF diet resulted in a significantly $(p=0.047)$ decreased FS in KO mice (Fig. 2).

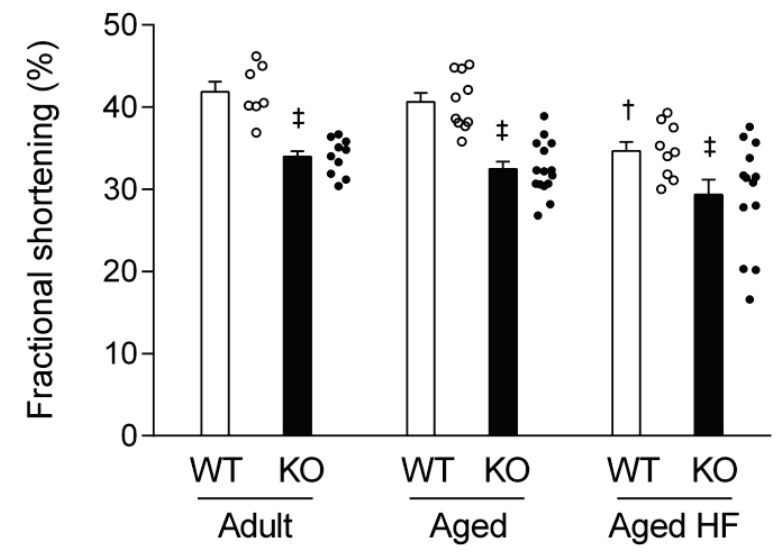

Fig. 2. Left ventricular fractional shortening in adult and aged AMPK $\mathrm{a}^{-1-}$ (KO) and wild-type (WT) mice fed standard or high-fat (HF) diet. Circles indicate individual experiments. Values are means \pm SEM; $\mathrm{n}=7-15$ in each group; ${ }^{\dagger} p<0.05$ vs. standard diet; ${ }^{\ddagger} p<0.05$ vs. WT.

\section{Coronary flow and infarct size}

Baseline preischemic coronary flow normalized to heart weight was comparable among groups regardless the age, diet or genotype, except for slightly but significantly higher values in aged WT hearts compared to adult ones. Coronary flow at the end of reperfusion was lower compared with preischemic values in all groups, but the difference was least pronounced in the aged WT group. AMPK $\alpha 2$-subunit deletion negatively affected the flow recovery in both age groups kept at standard diet. The HF diet-feeding tended to decrease the flow at reperfusion, but this effect reached statistical significance in the WT hearts only (Table 4).

Table 4. Coronary flow before ischemia and at the end of reperfusion in isolated perfused hearts of adult and aged AMPK $\mathrm{a}^{-{ }^{--}}$and wild-type mice fed standard or high-fat diet.

\begin{tabular}{lccc}
\hline \multicolumn{4}{c}{ Coronary flow (ml/g/min) } \\
\hline & $\mathbf{n}$ & Preischemic & Reperfusion \\
\hline Adult $W T$ & 8 & $13.3 \pm 1.0$ & $10.2 \pm 0.6$ \\
Adult $K O$ & 11 & $13.2 \pm 0.6$ & $8.1 \pm 0.5^{\ddagger}$ \\
Aged $W T$ & 11 & $17.8 \pm 1.3^{*}$ & $16.1 \pm 1.3^{*}$ \\
Aged $K O$ & 14 & $15.2 \pm 0.4$ & $10.1 \pm 0.9^{*}$ \\
Aged $W T H F$ & 11 & $15.0 \pm 1.6$ & $8.8 \pm 0.9^{\dagger}$ \\
Aged $K O H F$ & 11 & $13.3 \pm 0.9$ & $8.5 \pm 1.4$ \\
\hline
\end{tabular}

$\mathrm{KO}$, AMPK $\mathrm{a2}^{-1-}$ mice; WT, wild-type mice; HF, high-fat diet; $\mathrm{n}$, number of hearts. Values are means $\pm \mathrm{SE}^{*}{ }^{*} p<0.05$ vs. adult; ${ }^{+} p<0.05$ vs. standard diet; ${ }^{\ddagger} p<0.05$ vs. WT.

Infarct size was similar in both strains at the age of 6 months. Surprisingly, aging resulted in a significant infarct size-sparing effect in WT mice that was absent in animals with AMPK $\alpha 2$-subunit deletion. The HF diet abolished the age-associated improvement of myocardial ischemic tolerance in WT mice without significantly affecting KO mice. Nevertheless, the extent of injury was larger in the later group compared to WT animals (Fig. 3).

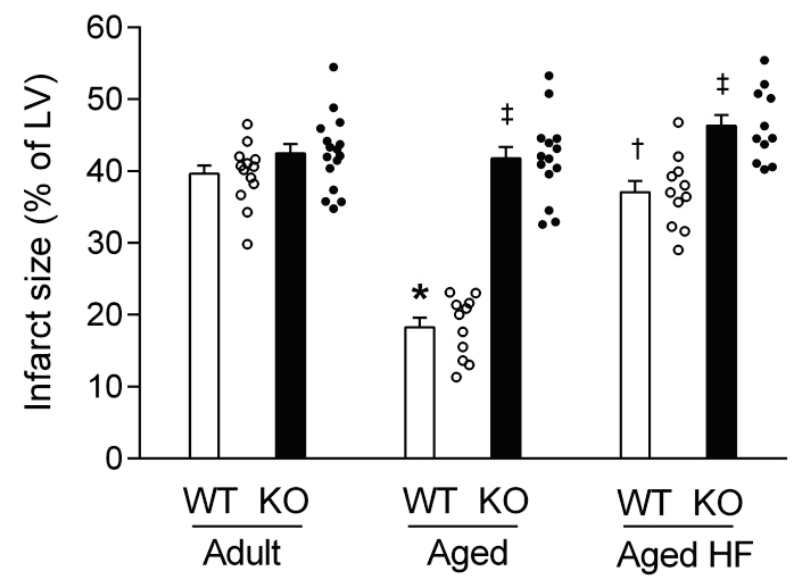

Fig. 3. Myocardial infarct size expressed as percentage of the left ventricle (LV) in adult and aged AMPK $\mathrm{a}^{-{ }^{--}}(\mathrm{KO})$ and wild-type (WT) mice fed standard or high-fat (HF) diet. Circles indicate individual experiments. Values are means $\pm S E M ; n=11-16$ in each group; ${ }^{*} p<0.05$ vs. adult; ${ }^{\dagger} p<0.05$ vs. standard diet; ${ }^{\ddagger} p<0.05$ vs. WT. 


\section{Discussion}

The results of the present study provide further evidence for the important role of AMPK $\alpha 2$-subunit in the regulation of processes associated with heart aging. Aged female mice exhibited decreased myocardial levels of both AMPK $\alpha 1$ - and $\alpha 2$-subunits and AMPK phosphorylation compared with adult littermates, the later effect being more pronounced in $\mathrm{KO}$ animals. The major finding is that AMPK $\alpha 2$-subunit deletion and HF feeding significantly impaired both cardiac contractile function and tolerance to acute $\mathrm{I} / \mathrm{R}$ injury in aged mice, but the negative effects of these two interventions were not additive to each other.

An increasing evidence suggests that AMPK activity can slow down aging process and extend the lifespan. AMPK is involved in a complex network of signaling pathways that control a number of cellular events helping to maintain energy balance under various stress conditions and the loss of AMPK responsiveness may contribute to age-related metabolic disturbances (Salminen and Kaarniranta 2012). However, reports concerning changes of AMPK expression and activity during aging and senescence are rather controversial. For example, Reznick et al. (2007) observed the loss of AMPK activation in skeletal muscle by AICAR or exercise in aged rats without any change in the expression of AMPK $\alpha 1$ - and $\alpha 2$-subunits. Similarly, aging impaired phosphorylation of AMPK $\alpha$-subunit in rat skeletal muscle but not the expression of either $\alpha 1$ - or $\alpha 2$-subunits (Qiang et al. 2007). In contrast, an increased AMPK activity with aging was observed in cultured human fibroblasts (Wang et al. 2003). Whereas the basal activity of AMPK $\alpha 1$-, but not $\alpha 2$-subunit, was higher in livers from old mice compared to young animals, hypoxiainduced activation was blunted with aging (Mulligan et al. 2005). Concerning the heart, neither basal activity of AMPK $\alpha 1$ - and $\alpha 2$-subunit, nor its stimulation by AMP was afected by age in mice (Gonzales et al. 2004), and no effect of aging on AMPK phosphorylation was found in human atrial tissue (Niemann et al. 2013). On the other hand, recent reports showed that aging or senescence did not affect murine myocardial AMPK expression, but it decreased its phosphorylation and activity as well as the specific activities of both AMPK $\alpha 1$ - and AMPK $\alpha 2$-subunits (Turdi et al. 2010, Aurich et al. 2013). In the presents study, we found significant decreases in protein levels of both $\alpha$-subunit isoforms and phosphorylated AMPK indicating its reduced basal activity in the hearts of aged mice that was futher attenuated in animals with a2-subunit deletion. Although the reason for these differences is unclear, our data are in line with the view that AMPK function is likely compromised in aged hearts.

Despite the fact that AMPK is highly expressed in the myocardium, its role in the pathogenesis of heart dysfunction associated with aging has not been fully understood. Our echocardiographic data clearly show that the left ventricular systolic function in both adult and aged $\mathrm{KO}$ mice was lower compared to WT animals as indicated by a decreased fractional shortening. This observation is in agreement with the study of Turdi et al. (2010), who demonstrated that the impairment of calcium handling and contractility of myocytes isolated from aged murine hearts was more pronounced in transgenic animals overexpressing a dominant negative AMPK a2-subunit (kinase dead). Moreover, aging-induced contractile defects were attenuated by treatment with the AMPK activator metformin. These data suggest that AMPK deficiency may contribute to age-induced cardiac dysfunction. It likely involves oxidative stress, impaired intracellular calcium handling and disrupted mitochondrial function (Turdi et al. 2010), but the complex mechanism remains to be elucidated.

The majority of studies that investigated an impact of aging on intrinsic cardiac tolerance to $I / R$ injury demonstrated its impairment with advanced age, possibly as a consequence of enhanced oxidative stress (for review see Boengler et al. 2009). Our observation of a reduced infarct size in female WT mice aged 18 months compared to their younger littermates can be, therefore, considered rather surprising. However, available evidence shows not only that aging is not always associated with exacerbated I/R injury (Azhar et al. 1999, Peart et al. 2007) but also that myocardial ischemic tolerance can improve with aging or senescence. For instance, several studies demonstrated infarct size reduction in aged rats (Sniecinski and Liu 2004), mice (Gould et al. 2002, Boengler et al. 2007, Przyklenk et al. 2008) or guineapigs (Rhodes et al. 2012). These discrepancies may be, in part, due to marked differences in the age of animals used in various studies often regardless their sex. Our preliminary observation that the infarct size reduction is absent in 18-month-old male mice (Slámová et al. 2012), points to an important role of sex. Interestingly, Willems et al. (2005) reported biphasic changes in the extent of myocardial injury caused by $I / R$ in mice that suggest a decreasing tolerance with aging and increasing 
tolerance with senescence; the developmental profile of these changes differed between males and females. It seems, therefore, that a certain sex-related window may exist during the aging process when intrinsic protective mechanisms are more active allowing the heart to better survive acute $\mathrm{I} / \mathrm{R}$ insult than at younger stages. It has been proposed that aging-associated cardioprotection may be linked to an attenuation of mitochondrial calcium overload (Rhodes et al. 2012) but the underlying mechanism is unknown at present. Although in the present study the AMPK $\alpha 2$-subunit deletion did not significantly worsen the extent of myocardial injury in young animals, the absence of infarct-sparing effect of aging in KO mice suggests that the AMPK pathway plays a role in this phenomenon.

Consistent with the view that high intake of fatty acids may cause cardiac lipotoxicity (Lopaschuk et al. 2007), here we show that feeding WT mice with HF diet for 6 months during aging decreased LV fractional shortening and impaired ischemic tolerance compared to their age-matched littermates fed standard diet. These results support a number of the previous reports indicating $\mathrm{HF}$ diet-induced cardiac contractile dysfunction (Ouwens et al. 2005, Relling et al. 2006, Turdi et al. 2011, Guo et al. 2013) and exacerbation of $\mathrm{I} / \mathrm{R}$ injury by increased levels of fatty acids (Lopaschuk et al. 2007, Thakker et al. 2008). However, it should be mentioned that other reports failed to demonstrate cardiac lipotoxicity and dysfunction following long term exposure to HF diet (Nascimento et al. 2011, Brainard et al. 2013) and this issue remains controversial. Besides the source of diet, the age of animals likely plays a role due to the inability of old myocytes to adapt to high fatty acid load (Aurich et al. 2013). In the present study, switch to HF diet took place at the age of 12 months when reproductive function of female $\mathrm{C} 57 \mathrm{BL} / 6 \mathrm{~J}$ starts to cease (Felicio et al. 1984) in association with neuroendocrine and hormonal changes that may also influence effects of the diet.

It has been shown that AMPK $\alpha 2$-subunit activity is important in the regulation of fatty acid uptake in HF diet-fed mice (Abbott et al. 2012). A limitation of our work is that we could not measure AMPK subunits activity in aged mice fed HF diet. However, earlier studies have demonstrated that HF diet decreases myocardial AMPK phosphorylation status and activity (Guo et al. 2013, Lindholm et al. 2013), these effects being more pronounced with advanced age (Aurich $e t$ al. 2013). In addition, AMPK $\alpha 2$-subunit deficiency exaggerates insulin resistance (Fujii et al. 2008), cardiac contractile dysfunction and impaired intracellular calcium handling (Turdi et al. 2011) induced by HF diet-feeding in middle age mice. In our experiments, the LV systolic dysfunction and ischemic intolerance in mice on HF diet was more pronounced in KO compared to WT group. However, these unfavourable effects of the HF diet did not reach statistical significance on the background of AMPK $\alpha 2$-subunit deletion. The reason for the absence of additive effects of HF diet and AMPK deficiency is unclear, but it can be related to the fact that both heart function and ischemic tolerance of aged $\mathrm{KO}$ mice fed standard diet were already compromised compared to WT animals, whereas any notable effect of AMPK deficiency itself was not observed in the study of Turdi et al. (2011) on younger mice. Alternatively, the defect in AMPK function may be apparent only under the conditions promoting lipogenesis, i.e. in the animals fed standard diet when activation of AMPK can increase fatty acid oxidation to preserve intracellular energy status, whereas AMPK inactivation likely remains silent when lipogenesis is heavily suppressed in response to HF dietfeeding. Our previous results on the functional significance of AMPK in the liver support the later possibility (Jeleník et al. 2010).

\section{Conclusions}

Here we demonstrate that aging resulted in significant AMPK downregulation and improved ischemic tolerance of female murine hearts. Global genetic ablation of AMPK $\alpha 2$-subunit or long-term feeding HF diet similarly resulted in cardiac dysfunction and abolished the anti-ischemic protection. However, the effects of AMPK a2-subunit deletion were not further potentiated by HF diet. Our findings support the view that AMPK activity plays a role in normal heart aging, suggesting this kinase as a potential target for cardioprotective interventions.

\section{Conflict of Interest}

There is no conflict of interest.

\section{Acknowledgements}

This work was supported by the Czech Science Foundation (14-36804G) and the institutional research project RVO:67985823. The authors thank Grahame Hardie for the sheep AMPK $\alpha 1$ - and $\alpha 2$-subunit antibodies and Benoit Viollet for the transgenic mice. 


\section{References}

ABBOTT MJ, CONSTANTINESCU S, TURCOTTE LP: AMP-activated protein kinase $\alpha 2$ is an essential signal in the regulation of insulin-stimulated fatty acid uptake in control-fed and high-fat-fed mice. Exp Physiol 97: 603-617, 2012.

ASHTON KJ, WILLEMS L, HOLMGREN K, FERREIRA L, HEADRICK JP: Age associated shifts in cardiac gene transcription and transcriptional responses to ischemic stress. Exp Gerontol 41: 189-204, 2006.

AURICH AC, NIEMANN B, PAN R, GRUENLER S, ISSA H, SILBER RE, ROHRBACH S: Age-dependent effects of high fat-diet on murine left ventricles: role of palmitate. Basic Res Cardiol 108: 369, 2013.

AZHAR G, GAO W, LIU L, WEI JY: Ischemia-reperfusion in the adult mouse heart influence of age. Exp Gerontol 34: 699-714, 1999.

BOENGLER K, KONIETZKA I, BUECHERT A, HEINEN Y, GARCIE-DORADO D, HEUSCH G, SCHULZ R: Loss of ischemic preconditioning's cardioprotection in aged mouse hearts is associated with reduced gap junctional and mitochondrial levels of connexin 43. Am J Physiol Heart Circ Physiol 292: H1764-H1769, 2007.

BOENNGLER K, SCHULZ R, HEUSCH G: Loss of cardioprotection with ageing. Cardiovasc Res 83: 247-261, 2009.

BRAINARD RE, WATSON LJ, DEMARTINO AM, BRITTIAN KR, READNOWER RD, BOAKYE AA, ZHANG D, HOETKER JD, BHATNAGAR A, BABA SP, JONES SP: High fat feeding in mice is insufficient to induce cardiac dysfunction and does not exacerbate heart failure. PloS One 8: e83174, 2013.

DYCK JR, LOPASCHUK GD: AMPK alterations in cardiac physiology and pathology: enemy or ally? $J$ Physiol 574: 95-112, 2006.

EDWARDS AG, DONATO AJ, LESNIEWSKI LA, GIOSCIA RA, SEALS DR, MOORE RL: Life-long caloric restriction elicits pronounced protection of the aged myocardium: a role for AMPK. Mech Ageing Dev 131: 739-742, 2010.

FELICIO LS, NELSON JF, FINCH CE: Longitudinal studies of estrous cyclicity in aging C57BL/6J mice: II. Cessation of cyclicity and the duration of persistent vaginal cornification. Biol Reprod 31: 446-453, 1984.

FERRARI AU, RADAELli A, CENTOLA M: Aging and the cardiovascular system. J Appl Physiol 95: 2591-2597, 2003.

FOLMES CD, WAGG CS, SHEN M, CLANACHAN AS, TIAN R, LOPASCHUK GD: Suppression of 5'-AMPactivated protein kinase activity does not impair recovery of contractile function during reperfusion of ischemic hearts. Am J Physiol Heart Circ Physiol 297: H313-H321, 2009.

FUJII N, HO RC, MANABE Y, JESSEN N, TOYODA T, HOLLAND WL, SUMMERS SA, HIRSHMAN MF, GOODYEAR LJ: Ablation of AMP-activated protein kinase alpha2 activity exacerbates insulin resistance induced by high-fat feeding of mice. Diabetes 57: 2958-2966, 2008.

GONZALEZ AA, KUMAR R, MULLIGAN JD, DAVIS AJ, SAUPE KW: Effects of aging on cardiac and skeletal muscle AMPK activity: basal activity, allosteric activation, and response to in vivo hypoxemia in mice. $A m J$ Physiol Regul Integr Comp Physiol 287: R1270-R1275, 2004.

GOULD KE, TAFFAT GE, MICHAEL LH, CHRISTIE RM, KONKOL DL, POCIUS JS, ZACHARIAH JP, CHAUPIN DF, DANIEL SL, SANDUSKY GE JR, HARTLEY CJ, ENTMAN ML: Heart failure and greater infarct expansion in middle-aged mice: a relevant model for postinfarction failure. Am J Physiol Heart Circ Physiol 282: H615-H621, 2002.

GUO R, ZHANG Y, TURDI S, REN J: Adiponectin knockout accentuates high fat diet-induced obesity and cardiac dysfunction: role of autophagy. Biochim Biophys Acta 1832: 1136-1148, 2013.

HARDIE DG: Minireview: the AMP-activated protein kinase cascade: the key sensor of cellular energy status. Endocrinology 144: 5179-5183, 2003.

HARDIE DG, CARLING D: The AMP-activated protein kinase-fuel gauge of the mammalian cell? Eur J Biochem 246: 259-273, 1997.

JELENÍK T, ROSSMEISL M, KUDA O, JÍLKOVÁ ZM, MEDŘÍKOVÁ D, KƯS V, HENSLER M, JANOVSKÁ P, MIKŠÍK I, BARANOWSKI M, GORSKI J, HEBRARD S, JENSEN TE, FLACHS P, HAWLEY S, VIOLLET $\mathrm{B}$, KOPECKÝ J: AMP-activated protein kinase $\alpha 2$ subunit is required for the preservation of hepatic insulin sensitivity by n-3 polyunsaturated fatty acids. Diabetes 59: 2737-2746, 2010. 
KUDA O, JELENÍK T, JÍLKOVÁ Z, FLACHS P, ROSSMEISL M, HENSLER M, KAZDOVÁ L, OGSTON N, BARANOWSKI M, GORSKI J, JANOVSKÁ P, KŮS V, POLAK J, MOHAMED-ALI V, BURCELIN R, CINTI S, BRYHN M, KOPECKÝ J: n-3 fatty acids and rosiglitazone improve insulin sensitivity through additive stimulatory effects on muscle glycogen synthesis in mice fed high-fat diet. Diabetologia 52: 941-951, 2009.

KUDO N, BARR AJ, BARR RL, DESAI S, LOPASCHUK GD: High rates of fatty acid oxidation during reperfusion of ischemic hearts are associated with a decrease in malonyl-CoA levels due to an increase in 5'-AMP-activated protein kinase inhibition of acetyl-CoA carboxylase. J Biol Chem 270: 17513-17520, 1995.

KŮS V, PRAŽÁK T, BRAUNER P, HENSLER M, KUDA O, FLACHS P, JANOVSKÁ P, MEDŘÍKOVÁ D, ROSSMEISL M, JÍLKOVÁ Z, ŠTEFL B, PASTALKOVA E, DRAHOTA Z, HOUŠTĚK J, KOPECKÝ J: Induction of muscle thermogenesis by high-fat diet in mice: association with obesity-resistance. Am J Physiol Endocrinol Metab 295: E356-E367, 2008.

LAKKATTA EG, SOLLOTT SJ: The "heartbreak" of older age. Mol Interv 2: 431-446, 2002.

LI J, COVEN DL, MILLER EJ, HU X, YOUNG ME, CARLING D, SINUSAS AJ, YOUNG LH: Activation of AMPK alpha- and gamma-isoform complexes in the intact ischemic rat heart. Am J Physiol Heart Circ Physiol 291: H1927-H1934, 2006.

LINDHOLM CR, ERTEL RL, BAUWENS JD, SCHMUCK EG, MULLIGAN JD, SAUPE KW: A high-fat diet decreases AMPK activity in multiple tissues in the absence of hyperglycemia or systemic inflammation in rats. J Physiol Biochem 69: 165-175, 2013.

LIU Q, DOCHERTY JC, RENDELL JC, CLANACHAN AS, LOPASHUK GD: High levels of fatty acids delay the recovery of intracellular $\mathrm{pH}$ and cardiac efficiency in post-ischemic hearts by inhibiting glucose oxidation. J Am Coll Cardiol 39: 718-725, 2002.

LOPASCHUK GD, FOLMES CD, STANLEY WC: Cardiac energy metabolism in obesity. Circ Res 101: 335-347, 2007.

MATĚJKOVÁ O, MUSTARD KJ, ŠPONAROVÁ J, FLACHS P, ROSSMEISL M, MIKŠÍK I, THOMASONHUGHES M, GRAHAME HARDIE D, KOPECKÝ J: Possible involvement of AMP-activated protein kinase in obesity resistance induced by respiratory uncoupling in white fat. FEBS Lett 569: 245-248, 2004.

MCCARTY MF: Chronic activation of AMP-activated kinase as a strategy for slowing aging. Med Hypotheses 63: 334-339, 2004.

MULLIGAN JD, GONZALEZ AA, KUMAR R, DAVIS AJ, SAUPE KW: Aging elevates basal adenosine monophosphate-activated protein kinase (AMPK) activity and eliminates hypoxic activation of AMPK in mouse liver. J Gerontol A Biol Sci Med Sci 60: 21-27, 2005.

NASCIMENTO AF, LUVIZOTTO RA, LEOPOLDO AS, LIMA-LEOPOLDO AP, SEIVA FR, JUSTULIN LA JR, SILVA MD, OKOSHI K, WANG XD, CICOGNA AC: Long-term high-fat diet-induced obesity decreases the cardiac leptin receptor without apparent lipotoxicity. Life Sci 88: 1031-1038, 2011.

NIEMANN B, PAN R, TESCHNER M, BOENING A, SILBER RE, ROHRBACH S: Age and obesity-associated changes in the expression and activation of components of the AMPK signaling pathway in human right atrial tissue. Exp Gerontol 48: 55-63, 2013.

OUWENS DM, BOER C, FODOR M, DE GALAN P, HEINE RJ, MAASSEN JA, DIAMANT M: Cardiac dysfunction induced by high-fat diet is associated with altered myocardial insulin signalling in rats. Diabetologia 48: 1229$1237,2005$.

PEART JN, GROSS ER, HEADRICK JP, GROSS GJ: Impaired p38 MAPK/HSP27 signaling underlies aging-related failure in opioid-mediated cardioprotection. J Mol Cell Cardiol 42: 972-980, 2007.

PRZYKLENK K, MAYNARD M, DARLING CE, WHITTAKER P: Aging mouse hearts are refractory to infarct size reduction with post-conditioning. J Am Coll Cardiol 51: 1393-1398, 2008.

QIANG W, WEIQIANG K, QING Z, PENGJU Z, YI L: Aging impairs insulin-stimulated glucose uptake in rat skeletal muscle via suppressing AMPK-alpha. Exp Mol Med 39: 535-543, 2007.

RELLING DP, ESBERG LB, FANG CX, JOHNSON WT, MURPHY EJ, CARLSON EC, SAARI JT, REN J: High-fat diet-induced juvenile obesity leads to cardiomyocyte dysfunction and upregulation of Foxo3a transcription factor independent of lipotoxicity and apoptosis. J Hypertens 24: 549-561, 2006. 
REZNICK RM, ZONG H, LI J, MORINO K, MOORE IK, YU HJ, LIU ZX, DONG J, MUSTARD KJ, HAWLEY SA, BEFROY D, PYPAERT M, HARDIE DG, YOUNG LH, SHULMAN GI: Aging-associated reductions in AMP-activated protein kinase activity and mitochondrial biogenesis. Cell Metab 5: 151-156, 2007.

RHODES SS, CAMARA AK, HEISNER JS, RIESS ML, ALDAKKAK M, STOWE DF: Reduced mitochondrial Ca2+ loading and improved functional recovery after ischemia-reperfusion injury in old vs. young guinea pig hearts. Eur J Clin Microbiol Infect Dis 31: 1551-1559, 2012.

SALMINEN A, KAARNIRANTA K: AMP-activated protein kinase (AMPK) controls the aging process via an integrated signaling network. J Mol Med 89: 667-676, 2012.

SLÁMOVÁ K, JANOVSKÁ P, PAPOUŠEK F, KOPECKÝ J, KOLÁŘ F: Influence of aging and high-fat diet on myocardial ischemic tolerance in mice with AMP-activated protein kinase a2-subunit deficiency. Act Nerv Super Rediviva 54: 100, 2012.

SNIECINSKI R, LIU H: Reduced efficacy of volatile anesthetic preconditioning with advanced age in isolated rat myocardium. Anesthesiology 100: 589-597, 2004.

STEINBERG GR, KEMP BE: AMPK in health and disease. Physiol Rev 89: 1025-1078, 2009.

THAKKER GD, FRANGOGIANNIS NG, ZYMEK PT, SHARMA S, RAYA JL, BARGER PM, TAEGTMEYER H, ENTMAN ML, BALLANTYNE CM: Increased myocardial susceptibility to repetitive ischemia with high-fat diet-induced obesity. Obesity 16: 2593-2600, 2008.

TURDI S, FAN X, LI J, ZHAO J, HUFF AF, DU M, REN J: AMP-activated protein kinase deficiency exacerbates aging-induced myocardial contractile dysfunction. Aging Cell 9: 592-606, 2010.

TURDI S, KANDADI MR, ZHAO J, HUFF AF, DU M, REN J: Deficiency in AMP-activated protein kinase exaggerates high fat diet-induced cardiac hypertrophy and contractile dysfunction. $J$ Mol Cell Cardiol 50: $712-722,2011$.

VIOLLET B, ANDREELLI F, JøRGENSEN SB, PERRIN C, GELOEN A, FLAMEZ D, MU J, LENZNER C, BAUD O, BENNOUN M, GOMAS E, NICOLAS G, WOJTASZEWSKI JF, KAHN A, CARLING D, SCHUIT FC, BIRNBAUM MJ, RICHTER EA, BURCELIN R, VAULONT S: The AMP-activated protein kinase alpha2 catalytic subunit controls whole-body insulin sensitivity. J Clin Invest 111: 91-98, 2003.

WANG W, YANG X, LÓPEZ DE SILANES I, CARLING D, GOROSPE M: Increased AMP:ATP ratio and AMPactivated protein kinase activity during cellular senescence linked to reduced HuR function. $J$ Biol Chem 278: 27016-27023, 2003.

WANG S, SONG P, ZOU MH: AMP-activated protein kinase, stress responses and cardiovascular diseases. Clin Sci 122: 555-573, 2012.

WILLEMS L, ZATTA A, HOLMGREN K, ASHTON KJ, HEADRICK JP: Age-related changes in ischemic tolerance in male and female mouse hearts. $J$ Mol Cell Cardiol 38: 245-256, 2005.

ZAHA VG, YOUNG LH: AMP-activated protein kinase regulation and biological actions in the heart. Circ Res 111: 800-814, 2012. 